\title{
Proposta Verde: aspectos de sustentabilidade em uma pequena marcenaria que utiliza madeira de demolição
}

Green Proposal: aspects of sustainability in a small carpentry that uses demolition wood

\author{
SAMPAIO, Cláudio Pereira de; Mestre; Universidade Estadual de Londrina \\ qddesign@hotmail.com
}

DOLZAN, João; Especialista; Universidade Positivo

joaodolzan@ig.com.br

\begin{abstract}
Resumo
O presente artigo apresenta resultados de um estudo que propõe a utilização do conceito de Ecoeficiência no sistema produtivo de uma marcenaria que utiliza madeira de demolição como matéria prima. Para isso, são abordados os conceitos de ecoeficiência, Produção mais limpa $(P+L)$ e ecodesign. Utilizou-se como metodologia o estudo de caso, tendo como ferramentas de coleta e análise de dados observação direta, registro audiovisual do processo produtivo, entrevistas com colaboradores e mapeamento do processo produtivo. A partir de sua implantação, os benefícios esperados são principalmente relacionados à dimensão ambiental e econômica da sustentabilidade.
\end{abstract}

Palavras-Chave: Ecoeficiência; Produção mais limpa; Ecodesign. Marcenaria.

\begin{abstract}
This article presents results of a study that proposes the use of the concept of eco-efficiency in the productive system of a small carpentry shop, which uses the demolition wood as raw material. For this, the article discusses the concepts of ecoffiency, Cleaner Production (CP) and ecodesign. The methodological approach includes the case study, by using data collection and analysis tools as direct observation, photographic and filmographic registration of the production process, interviews with the company workers and production process mapping. Because of its implementation, the expected benefits are mainly concerned to environmental and economical dimensions of sustainability.
\end{abstract}

Keywords: Eco-efficiency; Cleaner production; Eco-design. Carpentry.

\section{Introdução}

A ação humana sobre o meio ambiente é uma preocupação recente, porém, o modelo de produção urbano-industrial desencadeia a poluição ambiental das águas, do solo e do ar há muito tempo e a situação tem se agravado.

Em um sentido amplo, se faz necessário criar estratégias que reduzam a poluição associada ao esgotamento de recursos hídricos, às emissões atmosféricas e a geração de resíduos domésticos e industriais. Ao contexto industrial, implantar o conceito de ecoeficiência, ou seja, produzir bens e serviços melhores reduzindo continuamente o uso de recursos e a geração de resíduos é uma estratégia que comprovadamente traz vantagens para as principais

Projética Revista Científica de Design I Universidade Estadual de Londrina I V.2 I N.2 I Dezembro 2011 
Proposta Verde: aspectos de sustentabilidade ... madeira de demolição

dimensões da sustentabilidade, econômicas, porque evita perdas e reduz custos, proporciona também benefícios sociais e ambientais pela ação preventiva no manejo do meio ambiente, evitando danos à população, além de melhorar a imagem da empresa.

Este trabalho se propõe a desenvolver um estudo dos conceitos de ecoeficiência, Produção mais limpa $(\mathrm{P}+\mathrm{L})$ e Ecodesign, para investigar de forma sistêmica o processo produtivo e propor melhorias na gestão ambiental de uma pequena marcenaria com ênfase em madeira de demolição. Desta forma, o pensamento sistêmico compõe a abordagem metodológica do presente estudo.

\section{Ecoeficiência, Produção mais limpa $(\mathrm{P}+\mathrm{L})$ e Ecodesign}

A ecoeficiência é um conceito voltado para o campo empresarial que busca melhorias ambientais que potenciem benefícios econômicos. Visa agregar mais valor utilizando menos material e energia, permeia todos os setores da empresa e todas as fases do ciclo de vida do produto. Conforme a proposta do Conselho Empresarial Brasileiro para o Desenvolvimento Sustentável - CEBDES, a ecoeficiência é composta dos seguintes elementos a serem perseguidos:

\footnotetext{
- Reduzir o consumo de materiais com bens e serviços;

- Reduzir o consumo de energia com bens e serviços;

- Reduzir a dispersão de substâncias tóxicas;

- Intensificar a reciclagem de materiais;

- Maximizar o uso sustentável de recursos renováveis;

- Prolongar a durabilidade dos produtos;

- Agregar valor aos bens e serviços.
}

A partir disso, o desenvolvimento sustentável pode ser visto como uma vantagem competitiva. Segundo Lerípio (1997), a poluição é uma forma de desperdício e ineficiência dos processos produtivos, já que é a perda de matérias-primas e insumos na fabricação dos produtos.

Para reduzir esta perda, o gerenciamento de resíduos, a utilização racional das matériasprimas e a diminuição do consumo energético e dos insumos necessários são os requisitos principais na busca pela qualidade ambiental e ecoeficiência. A Produção mais limpa $(\mathrm{P}+\mathrm{L})$ consiste em uma avaliação técnica, econômica e ambiental do processo produtivo para identificar oportunidades de melhorias que possibilitem, portanto, a ecoeficiência. Está relacionada à redução de poluição na sua origem, sendo que o primeiro passo para a sua implementação consiste em criar um amplo programa de limpeza interna e avaliar quantitativamente quais resíduos e efluentes são gerados pelo processo de produção, orientada geralmente para resolver problemas ambientais como odor, poluição e geração de resíduos sólidos problemáticos.

Os fundamentos básicos para o sucesso dessa metodologia são:

- Plena adoção do programa pela alta administração da empresa;

-Efetiva participação dos níveis de gestão;

-Sensibilização dos funcionários, formação dos "ecotimes";

- Busca dos focos geradores de resíduos;

- Valoração das perdas;

-Identificação de alternativas de solução para as perdas na origem; 
- $\quad$ Quantificação dos ganhos econômicos, ambientais e sociais.

A Produção mais limpa é uma estratégia de melhoramento contínuo dos processos, produtos e serviços, qualidade de vida e meio ambiente. Aplica-se tanto ao processo produtivo quanto ao produto, neste último através do ecodesign.

Ecodesign significa um menor consumo de energia, água e matéria-prima para a mesma quantidade de produto, para gerar menos emissões e menos resíduos, implica assim em mudanças nos padrões de produção e também no padrão de consumo, na compreensão dos impactos ambientais associados ao ciclo de vida dos produtos e adoção de novas formas de gestão empresarial. Como conceito pode-se dizer que 'Ecodesign ou Desenvolvimento Ambientalmente Consciente do Produto é a concepção dos produtos com integração da dimensão ambiente [...] orientando no seu todo o processo de design'. Ao promover o ecodesign de um produto se faz necessário (PENEDA; FRAZÃO, 1995, p. 15):

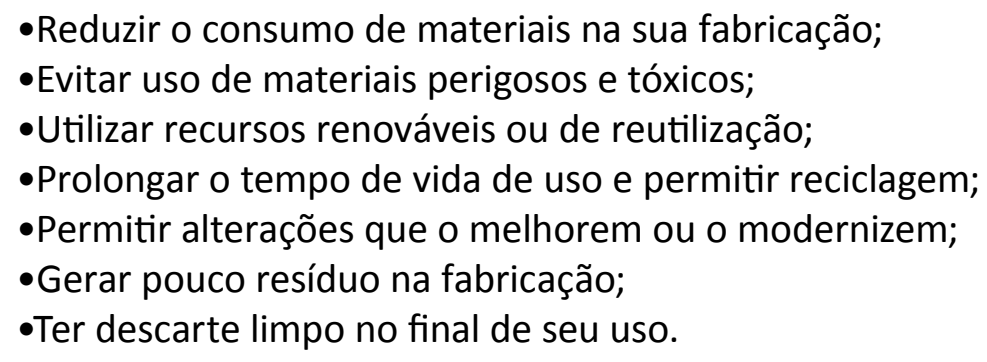

Ao conhecer os conceitos de ecoeficência, Produção mais limpa e ecodesign, fica evidente que são ferramentas gerenciais para a redução da poluição e melhoria da eficiência operacional. Portanto, qualquer tecnologia de gestão da produção voltada para a sustentabilidade, obrigatoriamente escolhe, caracteriza e classifica indicadores econômicos, ambientais e sócio-institucionais relacionados ao negócio.

\section{A empresa pesquisada e seu processo produtivo}

Esta pesquisa teve como cenário uma pequena marcenaria localizada em Ibirama, Santa Catarina, atuante no mercado desde 2007. A empresa conta com dois sócios proprietários, dois marceneiros e três auxiliares de produção, totalizando sete pessoas. A observação teve início com o reconhecimento do espaço físico da produção e elaboração do layout atual.

A empresa tem como sede um terreno com 5 hectares de mata atlântica preservada, conta com 1 galpão de $250 \mathrm{~m} 2$ onde ficam as máquinas e o almoxarifado, 1 galpão coberto de $150 \mathrm{~m} 2$ para a armazenagem de madeiras, 1 sala com $70 \mathrm{~m} 2$ que armazena portas, janelas e outros materiais vindos das demolições, 1 sala pequena para materiais de pintura e acabamento. Sabendo que o foco de estudo consiste na elaboração de um programa de Ecoeficiência, a observação foi direcionada para a produção.

Nesta primeira etapa já foi possível perceber a grande quantidade de resíduos gerados na marcenaria. 
Proposta Verde: aspectos de sustentabilidade ... madeira de demolição

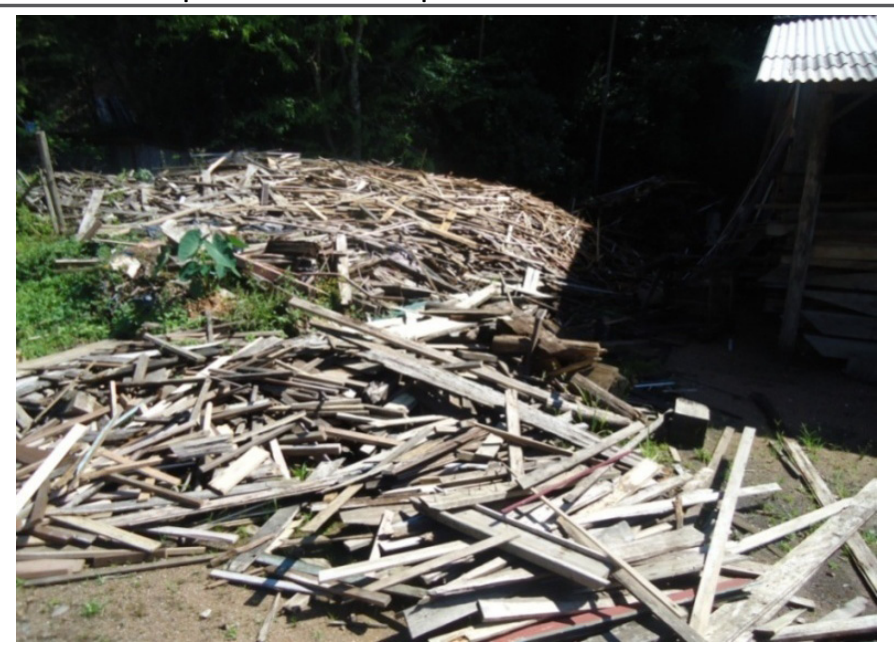

Figura 1 - Resíduos de madeira

Fonte: Arquivo pessoal (2010)

Estes resíduos são sobras de madeira que não foram aproveitadas no processo produtivo, são filetes, tocos, pequenas tábuas, ripas, etc.

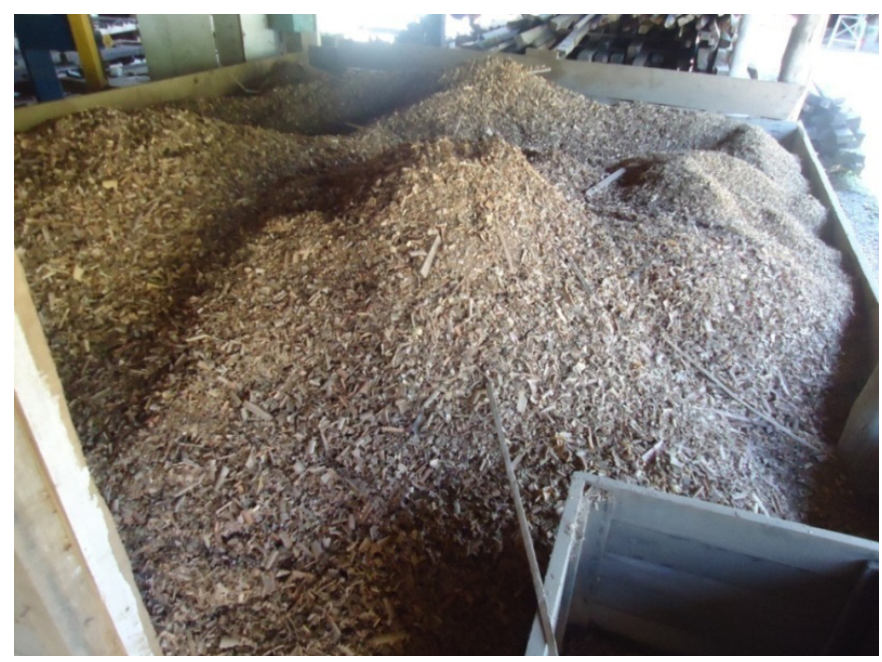

Figura 2 - Farelo de madeira

Fonte: Arquivo pessoal (2010)

O farelo e as sobras de madeira são os principais resíduos gerados na marcenaria pesquisada, porque são grandes quantidades de desperdício de matéria prima sem descarte satisfatório, segundo os responsáveis, o farelo é comercializado com raridade e a preço simbólico, já as sobras de madeira permanecem no pátio por não conhecerem uma forma adequada de descarte, fazem doações as pessoas da comunidade que buscam pequenas porções para usarem como lenha em seus fogões, o que não altera muito o volume estocado. Para a equipe, grande parte do que é jogado nesta montanha de lenha tem boa qualidade e poderia ser reutilizado no processo produtivo, porém, há escassez de mão de obra para selecionar estes materiais e falta espaço para armazená-los em lugar coberto.

Para entender como estes resíduos são gerados, foi elaborado um Fluxograma do processo em rede e um Fluxograma Qualitativo Global, ambos sugeridos pelo Guia PmaisL (CONSELHO EMPRESARIAL BRASILEIRO PARA O DESENVOLVIMENTO SUSTENTAVEL, 2010), a fim de conhecer todo o processo produtivo da empresa e suas fases. 


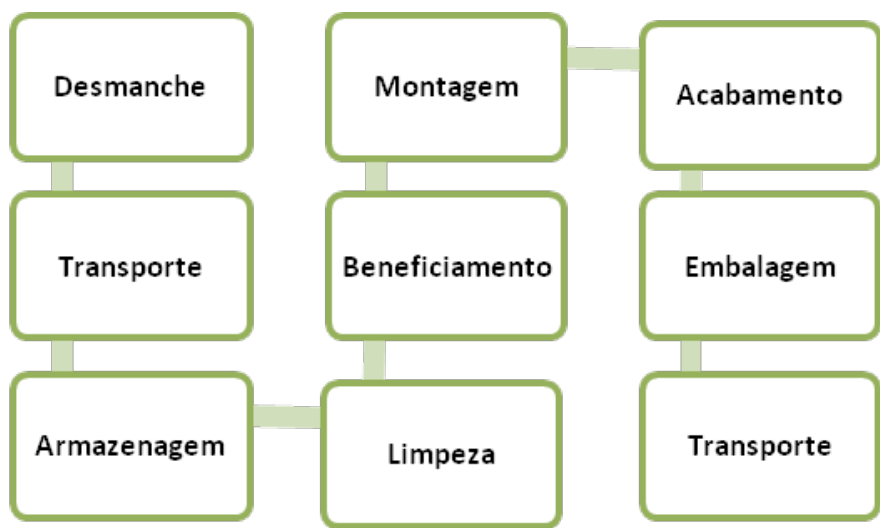

Figura 3 - Fluxograma do processo em rede

Fonte: Conselho Empresarial Brasileiro para o Desenvolvimento Sustentavel, 2010

Acompanhando o Fluxograma do processo em rede, percebe-se que o processo produtivo da marcenaria pesquisada inicia no desmanche de casas e galpões antigos, pois a madeira de demolição é a sua principal matéria-prima. Orlandi (2010), cita o designer Carlos Motta, segundo o qual [...] madeiras encontradas no mar ou rios, derrubadas pelo vento ou vindas de demolição tem hoje um nome técnico: madeira de redescobrimento.

A madeira de demolição ou de redescobrimento é uma matéria prima que oferece dupla vantagem ambiental. (MANZINI; VEZZOLI, 2002, p. 211) explica que a primeira vantagem está na anulação do impacto ambiental proveniente do despejo destes materiais no ambiente. $\mathrm{E}$ a segunda refere-se à disposição destes recursos não-virgens para a produção de novos materiais e energia.

Estender a vida dos materiais significa fazê-los viver por mais tempo do que duram os produtos que esses materiais estão compondo. Esta espécie de "reencarnação" dos materiais ocorre através de dois processos fundamentais, ou seja, os materiais podem ser reprocessados para serem transformados em matérias primas secundarias, ou incineradas para recuperar o seu conteúdo energético. (MANZINI; VEZZOLI, 2002, p. 211).

Deste modo, a madeira de demolição se enquadra no primeiro caso, pois é reutilizada para fabricar novos produtos, após ter completado um primeiro ciclo, cabe ressaltar que conseqüentemente árvores são preservadas. A utilização da madeira de demolição surgiu há aproximadamente dez anos, principalmente para a produção de móveis de estilo colonial.

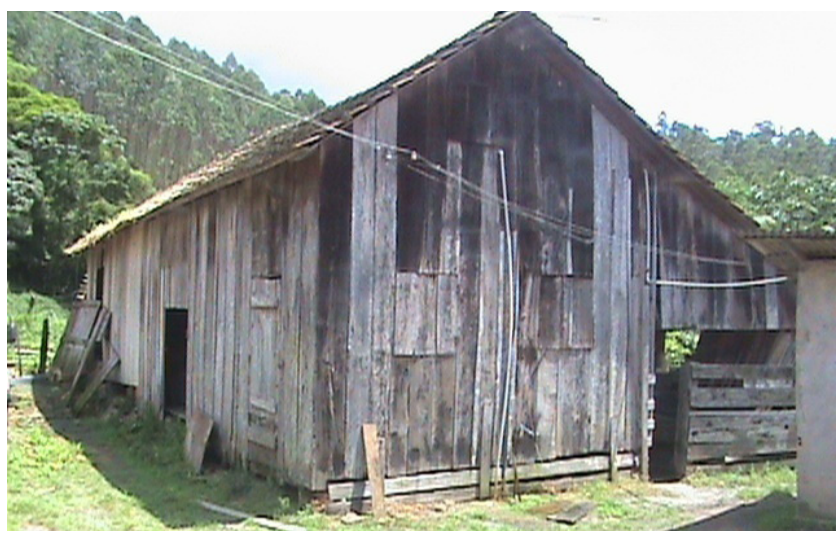

Figura 4 - Casa a ser demolida

Fonte: Arquivo pessoal (2010) 
Proposta Verde: aspectos de sustentabilidade ... madeira de demolição

Após o desmanche as madeiras são transportadas para a marcenaria onde são inspecionadas quanto à medida cúbica e quadradas, espessuras e qualidade, sendo então armazenadas a partir da classificação de suas medidas e espessuras.

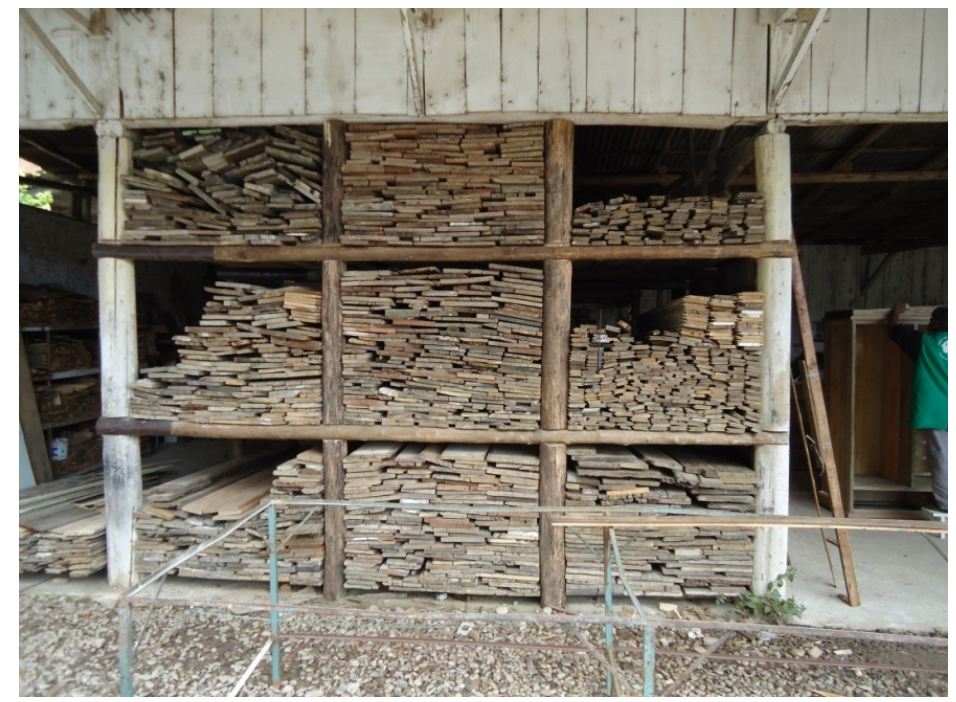

Figura 5 - Madeiras armazenadas

Fonte: Arquivo pessoal (2010)

Ainda de acordo com o Fluxograma de processo em rede, tendo a matéria-prima armazenada, estas são selecionadas conforme especificações do produto a ser produzido, considerando suas medidas, espécie e tom da madeira. Os auxiliares de produção selecionam a quantidade necessária e retiram pregos, parafusos e dobradiças manualmente. Esta fase denomina-se limpeza, da qual surgem os resíduos metálicos enferrujados.

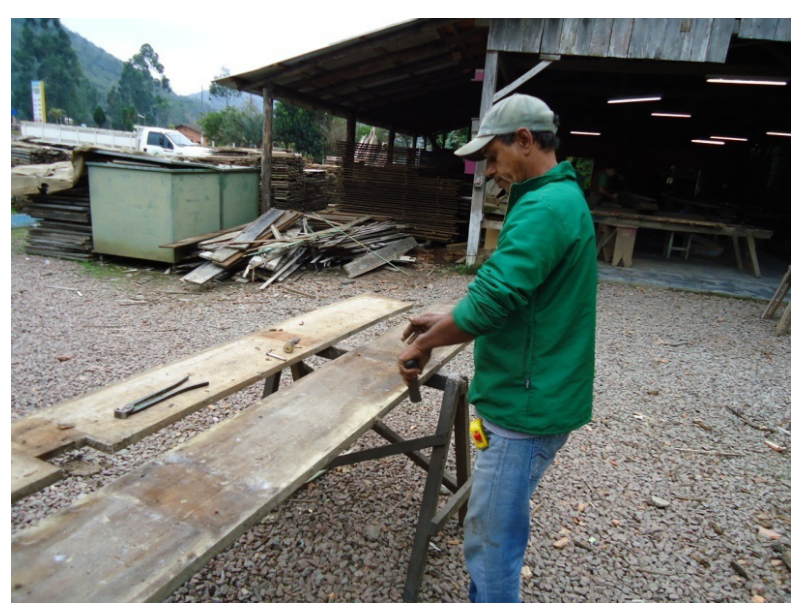

Figura 6 - Limpeza manual das madeiras

Fonte: Arquivo pessoal (2010)

Como a limpeza é feita de forma manual, um detector de metais é utilizado para evitar que peças metálicas danifiquem as máquinas no momento do beneficiamento.

O beneficiamento consiste em galopar as madeiras para que as laterais fiquem retas, esta máquina produz o farelo, em seguida passa pela serra de destopo para a retirada dos topos podres ou danificados, que são depositados no pátio, aumentando a cada dia a montanha de resíduos, por fim são passadas na desengrossadeira a fim de aparelhar as tabuas ou caibros 
Cláudio Pereira de Sampaio; João Dolzan

numa mesma espessura, esta última também gera o farelo.

Tendo a madeira beneficiada, os cortes, furos e lixações são feitos conforme especificações do produto, passando em seguida pela montagem, esta utiliza novos pregos, parafusos, cola, cavilhas, dobradiças e acessórios diversos.

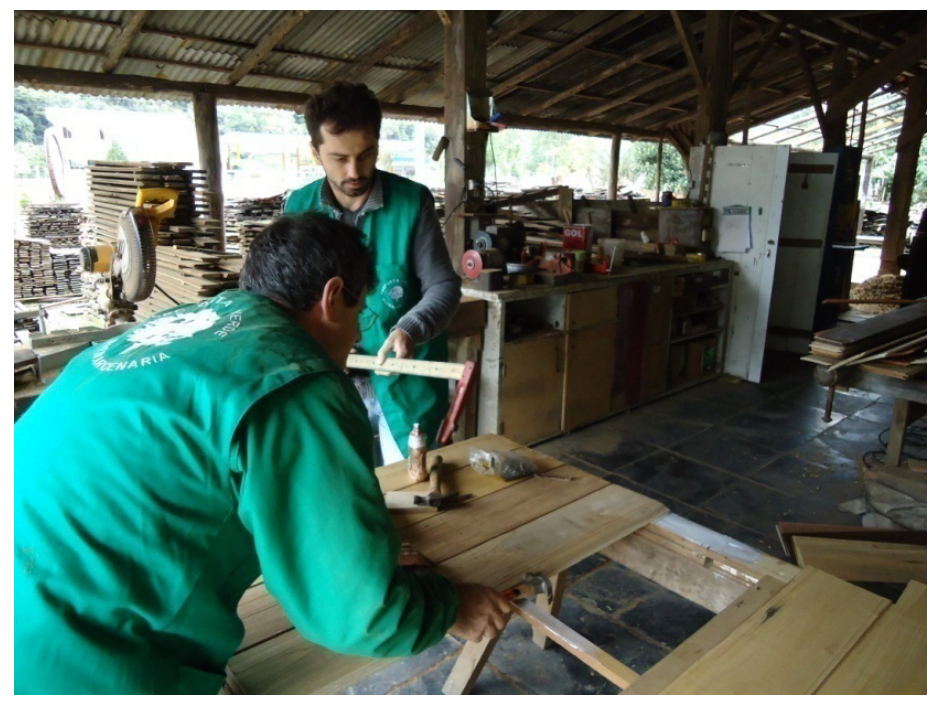

Figura 7 - Montagem do painel

Fonte: Arquivo pessoal (2010)

Com o produto montado o processo de acabamento é iniciado passando pela lixadeira que produz pó; depois, furos e emendas são tampados com o pó da lixadeira misturada com cola branca, pois forma uma massa da cor da madeira e tem função de acabamento e colagem; para retirar o excesso da massa, passa-se novamente pela lixa; depois, o produto é pintado com selador à base de água, lixado manualmente com uma lixa de folha fina ou lixa de disco, e, por fim, é encerado com cera de carnaúba.

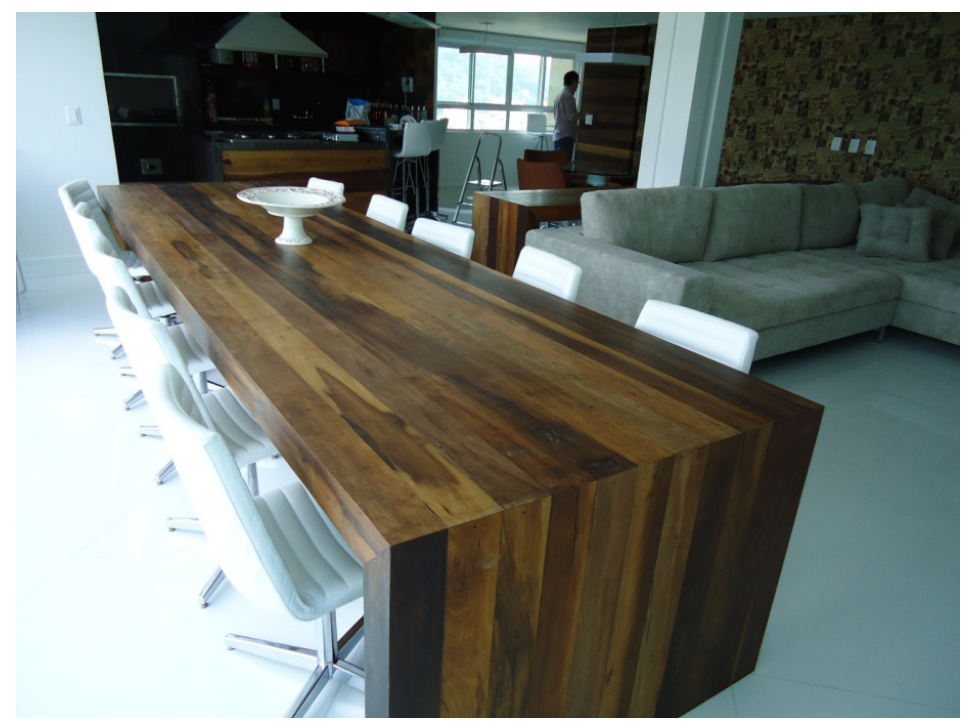

Figura 8 - Mesa de madeira de demolição Fonte: Arquivo pessoal (2010)

A embalagem utilizada é o "plástico-bolha", papelão e fita adesiva, mas segundo a equipe, com pouca freqüência é feita a embalagem, pois na maioria das vezes a própria empresa

Projética Revista Científica de Design I Universidade Estadual de Londrina I V.2 I N.2 I Dezembro 2011 
Proposta Verde: aspectos de sustentabilidade ... madeira de demolição faz as entregas e utiliza cobertores e lona para o transporte. Definindo-se o processo praticado pela empresa e identificando os resíduos gerados, as matérias-primas utilizadas e os produtos fabricados é possível elaborar o Fluxograma Qualitativo Global (CONSELHO EMPRESARIAL BRASILEIRO PARA O DESENVOLVIMENTO SUSTENTAVEL, 2010).

\section{Utilizando as ferramentas de $\mathrm{P}+\mathrm{L}$}

O Conselho Empresarial Brasileiro para o Desenvolvimento Sustentável - CEBDS criou através da Rede de Produção mais Limpa o "Guia P+L Faça você mesmo", que está disponível gratuitamente na internet. As ferramentas utilizadas neste capítulo pertencem a este guia. Do mesmo modo que o fluxograma do processo em rede elaborado antecipadamente a este capítulo é uma ferramentas do Guia Programa Produção mais limpa, outros quadros também fazem parte deste processo e foram utilizadas a seguir. Após este primeiro, passa-se a detalhar de forma organizada os resíduos gerados, as matérias-primas utilizadas e os produtos fabricados através dos fluxogramas Global e Intermediário.

\begin{tabular}{|l|l|l|}
\hline ENTRADAS & FÁBRICA & SAíDAS \\
\hline Tábuas & Mobiliários & Ruído \\
\hline Caibros & Pisos & Pó \\
\hline Sarrafos & Revestimentos & Farelo \\
\hline Forro & & $\begin{array}{l}\text { Sobras de } \\
\text { madeira }\end{array}$ \\
\hline Cola branca & & $\begin{array}{l}\text { Resíduos } \\
\text { químicos }\end{array}$ \\
\hline Lixas & & $\begin{array}{l}\text { Embalagens } \\
\text { plásticas }\end{array}$ \\
\hline Parafusos & & $\begin{array}{l}\text { Embalagens de } \\
\text { metal }\end{array}$ \\
\hline Pregos & & $\begin{array}{l}\text { Embalagens de } \\
\text { papel }\end{array}$ \\
\hline Energia elétrica & & $\begin{array}{l}\text { Metais } \\
\text { enferrujados }\end{array}$ \\
\hline Selador a base de água & & Lixas usadas \\
\hline Cera & & \\
\hline Tinta & & \\
\hline Acessórios metálicos & & \\
\hline
\end{tabular}

Quadro 1 - Fluxograma Qualitativo Global P+L.

Fonte: Conselho Empresarial Brasileiro para o Desenvolvimento Sustentavel (2010)

O Fluxograma Qualitativo Global (Quadro 1) representa toda a empresa e relaciona as principais matérias-primas consumidas, que são as Entradas, e os principais resíduos gerados, que são as Saídas. Com base no fluxograma qualitativo global, passa-se a elaboração do fluxograma qualitativo intermediário, utilizado para identificar as matérias-primas utilizadas em cada atividade e os resíduos gerados em decorrência de cada uma, este detalhamento faz 
Cláudio Pereira de Sampaio; João Dolzan

com que novas Saídas sejam percebidas (Quadro 2).

\begin{tabular}{|c|c|c|}
\hline ENTRADAS & FÁBRICA & SAÍDAS \\
\hline \multicolumn{3}{|l|}{ Tábuas } \\
\hline \multirow[t]{2}{*}{ Caibros } & Desmanche de casas & Madeiras podres \\
\hline & Limpeza & $\begin{array}{l}\text { Metais } \\
\text { enferrujados }\end{array}$ \\
\hline \multirow[t]{3}{*}{ Energia Elétrica } & Beneficiamento & $\begin{array}{l}\text { Pedaços de } \\
\text { madeira }\end{array}$ \\
\hline & & Farelo \\
\hline & & Pó \\
\hline Cola branca & Montagem & Resíduos químicos \\
\hline Parafusos & & $\begin{array}{l}\text { Embalagens de } \\
\text { papel }\end{array}$ \\
\hline Pregos & & $\begin{array}{l}\text { Embalagens } \\
\text { plásticas }\end{array}$ \\
\hline \multirow[t]{2}{*}{ Lixas } & & Pó \\
\hline & & Lixas usadas \\
\hline Selador a base de água & Acabamento & $\begin{array}{l}\text { Embalagens } \\
\text { metálicas }\end{array}$ \\
\hline Tinta & & Residuos químicos \\
\hline Cera & & Panos usados \\
\hline Plástico bolha & Embalagem & $\begin{array}{l}\text { Pedaços de } \\
\text { plásticos }\end{array}$ \\
\hline Fita adesiva & & $\begin{array}{l}\text { Pedaços de } \\
\text { papelăo }\end{array}$ \\
\hline Papelão & & \\
\hline
\end{tabular}

Quadro 2 - Fluxograma Qualitativo Intermediário P+L

Fonte: Arquivo pessoal (2010)

A utilização destes fluxogramas auxilia na percepção dos resíduos gerados na empresa, despertando deste modo uma visão holística consciente do processo produtivo. Este mapeamento possibilita a visualização dos principais problemas encontrados e, por conseguinte, direciona as ações para o melhoramento contínuo dos processos e dos produtos, uma vez que se passa a controlar quantitativamente a entrada e a saída descriminadas nos quadros.

É sabido que o processo de ecoeficiência deve ser visto como estratégia de longo prazo, preencher e controlar estes fluxogramas sistematicamente ajudará a empresa a organizar suas entradas e saídas de modo a reduzir a entrada, minimizá-las no processo produtivo e descartar corretamente as saídas através da separação dos resíduos. Para reduzir as entradas, formadas por matéria-prima, energia e insumos, torna-se útil a utilizar ferramentas de Ecodesign, pois esta ação está diretamente ligada ao produto.

Projética Revista Científica de Design I Universidade Estadual de Londrina I V.2 I N.2 I Dezembro 2011 
Proposta Verde: aspectos de sustentabilidade ... madeira de demolição

\section{Ecodesign e sua contribuição para a ecoeficiência}

Ecodesign está relacionado à gestão ambiental, voltado para o desenvolvimento de produtos que reduzam impactos ambientais e mantenham aspectos fundamentais como: funcionalidade, estética, qualidade e custo. Para isso, existem diversas ferramentas e métodos de ecodesign que possibilitam a avaliação dos impactos ambientais dos produtos em todo o seu ciclo de vida, identificando assim oportunidades de melhoria.

Para Manzini e Vezzoli (2002, p. 91) [...] no ciclo de vida considera-se o produto desde a extração dos recursos necessários para a produção dos materiais que o compõem (nascimento) até o último tratamento (morte) desses mesmos materiais após o uso do produto. 'Ainda segundo os autores, as fases que compõem o ciclo de vida de um produto são: pré-produção, produção, distribuição, uso e descarte, ou seja, todas as atividades necessárias para produzir, distribuir, utilizar e descartar um produto são consideradas uma só unidade. Manzini e Vezzoli não adotam o termo ecodesign, mas sim "design para a sustentabilidade", ou DfS. No entanto, diversos outros autores, ao abordar especificamente as questões ambientais e econômicas do design, utilizam o termo ecodesign, como um recorte mais específico dentro do DfS. Apesar disso, o conceito de life cycle design - LCD proposto por Manzini e Vezzoli é fundamental para a abordagem do ecodesign, e é explicado de forma bastante clara por estes autores.

Acadêmicos e praticantes desenvolveram e ainda desenvolvem muitas ferramentas de ecodesign, e, apesar da variedade, observam-se de modo geral alguns elementos fundamentais. Em consulta a Manzini e Vezzoli (2002, p. 105), foi elaborado o quadro abaixo com os principais elementos do ecodesign:

\begin{tabular}{|l|l|}
\hline O quê & Por quê \\
\hline Minimização dos recursos & Reduzir o uso de materiais e energia \\
\hline $\begin{array}{l}\text { Escolha de produtos e processos de } \\
\text { baixo impacto }\end{array}$ & $\begin{array}{l}\text { Selecionar materiais, processos e energia } \\
\text { eco-compatíveis }\end{array}$ \\
\hline Otimização da vida dos produtos & Projetar produtos que perdurem \\
\hline Extensão da vida dos materiais & Valorizar e reaplicar materiais descartados \\
\hline Facilidade de desmontagem & $\begin{array}{l}\text { Projetar para facilitar a separação das } \\
\text { partes e dos materiais }\end{array}$ \\
\hline
\end{tabular}

Quadro 3 - Estratégias para um produto ecoeficiente.

Fonte: Manzini e Vezzoli (2002, p. 105)

Ainda segundo os autores, o objetivo ambiental básico é reduzir ao mínimo possível o consumo de materiais, energia, do impacto de todas as emissões e dos descartes. Dessa perspectiva, as estratégias de minimização dos recursos e escolha de produtos e processos de baixo impacto seriam prioritárias.

Porém, colocando isso no contexto de ciclo de vida que considere a duração de um produto e a possibilidade de reutilização de seus componentes e materiais, torna-se prioritário partir das "estratégias de otimização da vida dos produtos" e da "extensão de vida dos materiais" (MANZINI; VEZZOLI, 2002, p. 106). Para decidir quais estratégias usar é necessário compreender as características do produto e seu sistema, além de definir prioridades em relação aos objetivos.

Considerando a empresa pesquisada, os produtos ali produzidos são mobiliários 
Cláudio Pereira de Sampaio; João Dolzan

e revestimentos de madeira de demolição. São bens duráveis que não requerem energia nem materiais durante o seu uso, deste modo, o seu impacto concentra-se nas fases de préprodução, produção, distribuição e descarte. A partir dessas informações, as estratégias de life cycle design podem ser escolhidas. Com base em Manzini e Vezzoli (2002, p.105-107) foi elaborado o quadro abaixo, com as estratégias adequadas para a empresa pesquisada.

\begin{tabular}{|c|c|c|}
\hline Fase do ciclo de vida & $\begin{array}{l}\text { Estratégias de bofe cycle } \\
\text { design }\end{array}$ & Exemplos de como fazer \\
\hline Pré-producbo e Produçà & $\begin{array}{l}\text { - Minimizar o consumo e } 0 \\
\text { impacto dos recursos } \\
\text { - Escollha dos materiais e } \\
\text { dos proxesses de baiso } \\
\text { impacto }\end{array}$ & 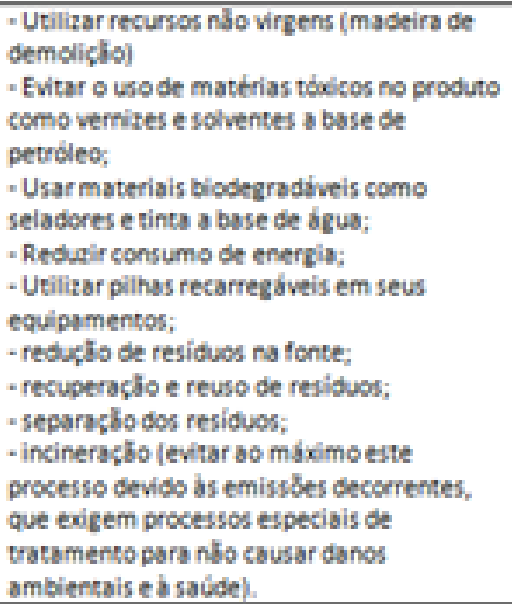 \\
\hline Distribuiçăo & $\begin{array}{l}\text { - Mirimizar o consumo de } \\
\text { energia e recursos }\end{array}$ & 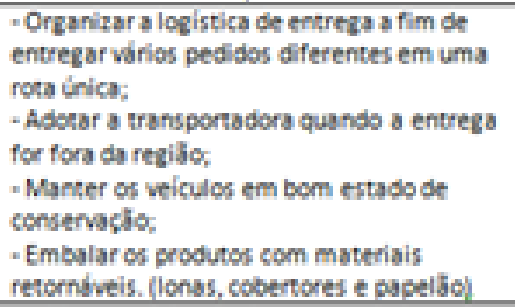 \\
\hline Descarte & $\begin{array}{l}\text { - Extens bo da vida dos } \\
\text { materisis } \\
\text { - Facilidade de } \\
\text { desmontagem }\end{array}$ & 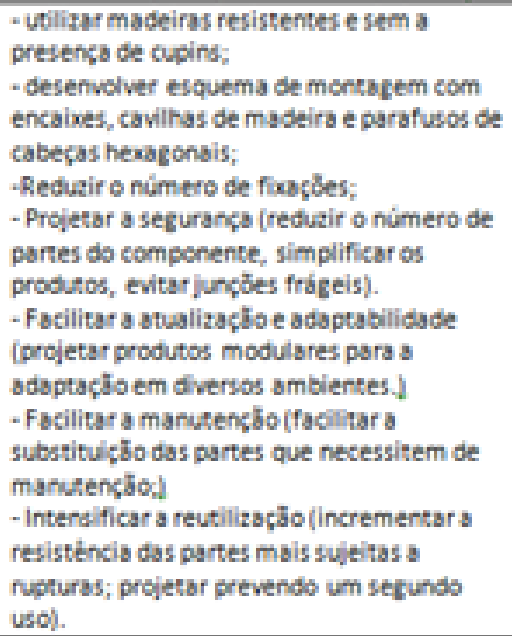 \\
\hline
\end{tabular}

Quadro 4 - Estratégias de life cycle design - LCD para a empresa pesquisada.

Fonte: Elaborado com base em Manzini e Vezzoli (2002, p. 105-107)

Ao analisar cada fase do produto, torna-se mais evidente as precauções a serem tomadas para evitar impactos desnecessários. Em resumo, qualquer proposta de cunho ambiental deve contextualizar o ciclo de vida e todos os processos necessários para a confecção de um produto. Além disso, a adoção de ferramentas de ecodesign e produção mais limpa no sistema de produção fazem com que o empreendedor passe a considerar sob sua responsabilidade os impactos gerados por materiais e ações.

Projética Revista Científica de Design I Universidade Estadual de Londrina I V.2 I N.2 I Dezembro 2011 
Proposta Verde: aspectos de sustentabilidade ... madeira de demolição

As ferramentas de ecodesign, para Manzini e Vezzoli (2002, p. 291) têm como principais objetivos: a definição de um quadro das interações entre uma determinada atividade e o ambiente; contribuir para a compreensão da complexidade e das conseqüências ambientais dessa atividade; fornecer informações que definem os efeitos das ações no ambiente das atividades e que propõem condições de melhorias das condições ambientais.

Ainda segundo os autores, o conhecimento sobre o meio ambiente é complexo e tornase difícil defini-lo com um modelo único, deste modo, as relações de causa e efeito não são facilmente identificáveis. Há ainda a indisponibilidade dos dados quantitativos, que no geral não são seguros e não estão facilmente disponíveis. Porém, dentro do quadro de desenvolvimento sustentável, em que se requer flexibilidade e inovação, as decisões podem ser tomadas inicialmente através de posicionamento político, com base em aspectos qualitativos.

Para obter sucesso no processo de ecodesign, é fundamental aproveitar as mudanças no sentido positivo de agregar valor, tanto para o fabricante quanto para a sociedade, pois os principais benefícios gerados são do interesse de todos: a redução de matérias-primas e por conseqüência a diminuição dos impactos ambientais.

\section{Considerações Finais}

Este estudo não priorizou o aprofundamento teórico sobre os conceitos de ecoeficiência, produção mais limpa e ecodesign; o propósito consistiu em introduzir fundamentos e ferramentas destes três conceitos, relacionando-os à realidade de uma pequena marcenaria com ênfase em madeira de demolição.

O caminho para a sustentabilidade é um processo de adaptação que só poderá ser atingido com a aprendizagem. Dentro do sistema de produção e consumo, as empresas possuem os maiores recursos de conhecimento e capacidade transformadora. Neste sentido, o sucesso da implantação de práticas voltadas para a sustentabilidade dependerá ainda de muito estudo, avaliação, quantificação e criatividade para inovar. A organização de projeto para a ecoeficiência requer ainda avanços na cultura organizacional e reorientação de práticas gerenciais e produtivas. A adoção de ferramentas de ecodesign e produção mais limpa no sistema de produção fazem com que o empreendedor passe a considerar sob sua responsabilidade os impactos gerados por materiais e ações.

No entanto, este estudo revelou ser possível iniciar o processo de transição para a sustentabilidade mesmo em uma pequena empresa. Sabendo que a estratégia de ecoeficência traz resultados em longo prazo, este estudo se propôs a conhecer os processos que empresa faz rotineiramente, detalhar suas entradas e saídas e considerar todas as fases do ciclo de vida de seus produtos. Isto fez com que se formasse uma visão holística do negócio ampliando a percepção de seus impactos ambientais, direcionando as perspectivas para encontrar os principais problemas e também algumas ações preventivas e corretivas para sua transformação rumo ao desenvolvimento sustentável.

\section{Referências}

CONSELHO EMPRESARIAL BRASILEIRO PARA O DESENVOLVIMENTO SUSTENTAVEL. Guia de produção mais limpa: faça você mesmo. Disponível em: <http://www.wbcsd.org/DocRoot/ ciFpL5hcUN7XBAQBe8lu/guia-da-pmaisl.pdf>. Acesso em: 10 dez. 2010.

LERIPIO, A. Emissão zero: um novo conceito de qualidade total. Florianópolis: UFSC, 1997. 
Cláudio Pereira de Sampaio; João Dolzan

MANZINI, E.; VEZZOLI, C. O desenvolvimento de produtos sustentáveis: os requisitos ambientais dos produtos industriais. São Paulo: Editora da Universidade de São Paulo, 2002.

ORLANDI, A. P.. Onda Étnica: Um Passeio Por Cinco Lojas De Decoração Alternativas Revela Como Decorar A Casa Com Toda A Diversidade Cultural Que O Planeta Oferece - Carlos Motta. Disponível em: <http://webcache.googleusercontent.com/search?q=cache:PNI-tYtst9wJ:www. privatebrokers.com.br/edicoes/artigo.asp\%3Fcod\%3D11+madeiras+encontradas+no+mar+ou +rios,+derrubadas+pelo+vento+ou+vindas+de+demoli\%C3\%A7\%C3\%A3o+tem+hoje+um+no me+t\%C3\%A9cnico:+madeira+de+redescobrimento\&cd=1\&hl=pt-BR\&ct=clnk\&gl=br>. Acesso em: 12 out. 2011.

PENEDA, C.; FRAZÃO, R. Ecodesign no desenvolvimento dos produtos. Lisboa: INETI, 1995. 